\title{
25 Research Soure \\ Pelvic and Bladder Catecholamine-Producing Tumors A Review of the Literature
}

\section{Luigi Petramala}

Department of Translational and Precision Medicine, "Sapienza" University of Rome

\section{Valeria Bisogni}

Department of Translational and Precision Medicine, "Sapienza" University of Rome, Italy

\section{Federica Olmati}

Department of Translational and Precision Medicine, "Sapienza" University of Rome

\section{Antonio Concistrè}

Department of Translational and Precision Medicine, "Sapienza" University of Rome

\section{Monia Celi}

Department of Translational and Precision Medicine, "Sapienza" University of Rome

\section{Vincenza Saracino}

Department of Translational and Precision Medicine, "Sapienza" University of Rome

\section{Gino lannucci}

Department of Translational and Precision Medicine, "Sapienza" University of Rome

\section{Giorgio De Toma}

"Pietro Valdoni" Surgery Department, "Sapienza" University of Rome

\section{Maria Rita Tarallo}

"Pietro Valdoni" Surgery Department, "Sapienza" University of Rome

\section{Antonio Ciardi}

Department of Radiological, Oncological and Anatomy-Pathological Sciences, "Sapienza" University of Rome

\section{Claudio Letizia ( $\square$ claudio.letizia@uniroma1.it)}

Universita degli Studi di Roma La Sapienza Facolta di Medicina e Odontoiatria https://orcid.org/00000003-4397-0624

\section{Review}

Keywords: pelvic paraganglioma, bladder paraganglioma, arterial hypertension, cardiovascular complications.

Posted Date: December 31st, 2019

DOI: https://doi.org/10.21203/rs.2.17185/v3 
License: (c) (i) This work is licensed under a Creative Commons Attribution 4.0 International License. Read Full License 


\section{Abstract}

Purpose . Starting from the description of two interesting cases, we wondered to review the literature on pelvic and bladder paragangliomas (PGLs) in order to illustrate clinical characteristics and current management, lightening the needed of a prompt diagnosis to avoid the onset of several complications. Although PGLs may arise at any site where physiologically chromaffin tissue exists, pelvic origins are not frequent (less than $2 \%$ ), and the most common localization is the retroperitoneal space, whereas bladder PGLs account for less than $0.06 \%$ of all bladder neoplasms and less than $1 \%$ of all PGLs. Methods. We herein performed a brief review of the literature about pelvic PGLs in the PubMed library, conducted according to the PRISMA statement, including studies published from 1954 to 2019 . We also discuss clinical presentation, morphologic appearance, and management of two cases of pelvic PGL, both of them characterized by an history of paroxysmal high blood pressure episodes uncontrolled by antihypertensive therapy associated with disabling symptoms, not clearly understood for many years. Results . Overall, we evaluated 108 case reports. The majority were females, presenting typical signs and symptoms, such as arterial hypertension (54.2\%), hematuria (35.1\%), and headache (33.6\%). After treatment, the clinical and biochemical remission was evident in only $55 \%$ of analyzed cases. Conclusions . For their singular localization, pelvic and bladder PGLs often might be misdiagnosed. The significant delay in the proper treatment could be responsible for the relative low percentage of complete clinical and biochemical remission.

\section{Background}

Less than $20 \%$ of chromaffin-cell tumors are paragangliomas (PGLs), which derived from extra-adrenal chromaffin cells of the sympathetic paravertebral ganglia of thorax, abdomen, and pelvis [1]. Most of them are characterized by oversecretion of catecholamines (i.e. epinephrine, norepinephrine, and dopamine), and with pheochromocytoma (PHEO) represent a rare cause of secondary hypertension (0.2 - $0.6 \%$ in adults) [12]. However, if not promptly recognized and treated, PGLs are associated to increased cardiovascular morbidity and mortality risk [3-5]. In non-syndromic cases, in fact, patients affected by PGLs can report a wide range of symptoms, including high blood pressure (BP) and uncontrolled paroxysmal hypertension episodes, accompanied by palpitations, headache, excessive sweating, facial pallor or flushing during the attack, chest and/or abdominal pain [6-8].

Pelvic PGLs represent only the $2 \%$ of overall localization with higher incidence in women [9]. The importance of accurate biochemical screening and specific imaging to recognize extra-adrenal catecholamine-secreting tumors is necessary to avoid misdiagnosis and, consequently, allowing the onset of associated complications.

The aim of our brief review is to illustrate the spectrum of clinical and radiological characteristics of pelvic PGLs, and the current treatment. We also present two original and singular cases of pelvic PGLs; the first one localized into bladder wall, misdiagnosed for many years despite referred typical signs and symptoms during micturition. The second case regards older woman, affected by arterial hypertension with multiple 
localizations of PGL, one of these sited anteriorly to the right common iliac artery at the bifurcation and probably responsible for clinical manifestations.

\section{Methods}

\section{Search strategy}

This study was performed according to the Preferred Reporting Items of Systematic Review and Metaanalysis (PRISMA) guidelines [10]. We conducted a literature search from January 1954 to February 2019 using the PubMed database looking for studies conducted on patients affected by pelvic and/or bladder PGL to resume the clinical and operatory management of pelvic PGL. The search terms were as follow: "pelvic paraganglioma" [AND/OR] "bladder paraganglioma", [AND/OR] "extra-adrenal pheochromocytoma"

\section{Inclusion/exclusion criteria}

Literature search was conducted by two reviewers and only case reports were considered. 297 manuscripts have been evaluated and 108 were eligible in the interest of providing fuller informations [11-85], in which were described a total of 131 case reports, 22 concerning pelvic PGLs and 109 bladder PGLs (Figure 1).

Veterinarian texts, papers with inadequate information, and cases in which only the abstract was available excluded. Studies were screened for eligibility based on title and abstract. Relevant articles were inspected in full text and publications that matched our inclusion criteria were included.

\section{Data extraction}

Data extraction was performed by one reviewer. Extraction was performed using the standard templates including details on study design (patients, index test, and referential standard), baseline characteristics (author, year of publication, mean age, sex, location of tumors, diagnosis, and therapies). Missing values were calculated from the available data if possible.

\section{Statistical analysis}

Data was analyzed using SPSS (version 24 for Mac; IBM, SPSS ${ }^{\circledR}$ Statistics, Italy) and GraphPad Prism software (version 8.0, GraphPad® Software Inc, San Diego, CA, USA). Significance was set at $P<0.05$.

\section{Results}

Most of patients were females ( $51.9 \%$ vs. $48.1 \%$ males) and the mean age at diagnosis was $40.4 \pm 18.8$ years. The average diameter of PGLs was $48.1 \pm 32.7 \mathrm{~mm}$ and the mean follow-up reported was $22 \pm 18$ months. In Table 1 we reported main characteristics of all cases examined, including signs and symptoms of presentation; most frequent were arterial hypertension (54.2\%), hematuria (35.1\%), and headache (33.6\%). Interestingly, we found two gynecological cases, in which the onset disease was characterized by preeclampsia $[16,19]$. In only ten cases were described a syndromic form of PGL (Table 1). Computed tomography (CT) scan and/or magnetic resonance (MR) were used in the imaging of all cases, however the 
${ }^{123}$ I-MIBG was performed in only 25 cases. In Table 1 we also listed the biochemical features. In particular we found that in less than $50 \%$ of cases 24 -hour urinary metanephrines, plasma catecholamines, and plasma metanephrines were positive. Lastly, most of cases reported in literature were treated by surgical tumor excision; some of these underwent mass embolization before surgical treatment. The group of patients with multiple localizations, metastatic, and more aggressive forms accounted for $34.3 \%$ of total and most of these patients underwent radiation therapy (after or before surgical tumor excision).

\section{Case Reports}

Case 1. In 2017 a young woman of 21 years old referred to our Unit complaining for recurrent micturition episodes of throbbing frontal headache, associated to increased blood pressure (BP) values, palpitation, nausea, and flushing at legs. In the previously four years, these episodes had been described but underestimated, and the patient was evaluated for a psychiatric disorder. She did not perform any diagnostic test, except for an abdominal CT scan with contrast that showed a suspected uterine mass (Figure 2, panel A), but she did not investigate it further. She had no family history for primary or secondary arterial hypertension, for metabolic and cardiovascular diseases. The 24-hour ambulatory blood pressure monitoring (24-h ABPM) showed BP paroxysms (up to $160 / 100 \mathrm{mmHg}$ ) mostly during micturition (episodes that matched with the self-reported daily diary). We hence performed hormonal screening tests for secondary hypertension. In particular, several measurements of 24-h urinary metanephrines and vanillyl mandelic acid (VMA) were into the normal range (74.0 $\mu \mathrm{g} / 24 \mathrm{~h}$, n.v. 0-350; $5.2 \mu \mathrm{g} / 24 \mathrm{~h}$, n.v. 1-10, respectively). However, symptoms were very suggestive for catecholamine-producing tumor, and we decided to repeat an abdominal imaging study. Patient underwent to abdominal MR that showed a thickwalled left adnexal mass ( $45 \times 20 \mathrm{~mm}$ ) abutting the urinary bladder (Figure 2, pane/B), which was confirmed by ${ }^{123}$-metaiodobenzylguanidine (MIBG) scintigraphy as strongly uptaking tumor (Figure 2, pane/ C). After optimization of BP paroxysms with an a-adrenergic receptor blocker (e.g. doxazosin $2 \mathrm{mg}$ b.i.d.) and pre-operative intravenous administration of fluids, considering the site and the large dimensions of this tumor, laparotomic surgery was performed and it was removed without complications (Figure 2, pane/ D). The histologic examination revealed trabecular pattern of polygonal shaped cells in rich vascular network characterized by finely granular basophilic cytoplasm and intracytoplasmic hyaline globules, confirming diagnosis of bladder paraganglioma. Genetic testing for the most common and newest genetic mutations associated to PGLs, such as succinate dehydrogenase (SDH) genes, resulted negative.

after 12-month follow-up our patient was completely asymptomatic, she denied the recurrence of micturition signs and symptoms, her BP values were well-controlled without therapy, and the pelvic MR imaging confirmed the absence of bladder lesions.

Case 2. A 76-year-old woman referred to our Unit complaining of paroxysmal arterial hypertension, poorly controlled by antihypertensive drugs, and asymptomatic for tachycardia, headache, and flushing. She denied a family and personal medical history of cardiovascular and metabolic diseases. However, the patient carried out a recent carotid Doppler ultrasonography, in which had been reported a mass of $18 \times 14$ $\mathrm{x} 21 \mathrm{~mm}$ diameters involving the right carotid glomus, close to the right siphon, confirmed by the following MR imaging. 
The suspicious was strongly addressed to a carotid PGL, thus, we performed a hormonal screening test. However, the 24-h urinary metanephrines levels were normal in two consecutive measurements (59 and 97 $\mu \mathrm{g} / 24$ h, n.v. $0-350$ ). The total body CT scan showed, besides the right carotid tumor, a mass of $52 \times 38 \times$ $46 \mathrm{~mm}$ diameter in the right pelvis, anteriorly to the right common iliac artery at the bifurcation (Figure 3 , panel A). This was described as high contrast enhancement oval mass with clear margins. The strongest uptake of ${ }^{123}$ I-MIBG deposed for a pelvic PGL (Figure 3, pane/B), while the right carotid glomus did not show contrast uptake. Therefore, after a proper pre-operative optimization of antihypertensive therapy (e.g. doxazosin $4 \mathrm{mg}$ twice per day) and fluids administration, the patient underwent laparotomic surgery to remove the right pelvic mass, without complications (Figure 3, panels $\mathrm{C}$ and D). Histologic examination confirmed our suspect, describing a well-delimitated PGL without signs of vascular invasion. At 6 months follow-up the office and 24-ABPM blood pressure values were normalized with no medications. Also in this case genetic test for PGL associated genes was negative for mutations. Unfortunately, the patient refused surgical removal of right carotid PGL, but she is now strictly monitored with several and scheduled clinical and biochemical evaluations, and annual radiological imaging, to avoid the onset of complication and/or disease exacerbation.

\section{Discussion}

Most of catecholamine-producing tumors appear in the adrenal medulla, however, about $10 \%$ of those arise from extra-adrenal chromaffin tissue and are called paragangliomas. In decreasing order of frequency, PGLs may develop: (i) in the Zuckerkandl body, a vestigial chromaffin ganglion located at the root of the upper mesenteric artery; (ii) in the sympathetic plexus of the urinary bladder, kidneys, and heart; or (iii) in sympathetic ganglia in the mediastinum, head or neck. Most head and neck PGLs are non-secreting [83], as in our second case report.

PGLs are relative rare in general population, occuring mainly in adults and usually benign; nonetheless the prevalence of malignant forms is about 30-40\% [1]. Moreover, these tumors might present multiple localizations (in about $30 \%$ of cases), but in less than $5 \%$ of non-familial types [1]. PGLs can be classified as functional and non-functional types [83], depending on the capacity to produce different types of catecholamines (e.g. epinephrine, norepinephrine, and dopamine) and their metabolites. A specific parade symptom belongs to epinephrine excess, such as headache, palpitation, diaphoresis, flushing, and paroxysmal and/or sustained hypertension. Various phenotypical presentation depends on various productions of catecholamine metabolites, such as 3-methoxytyramine, normetanephrine and metanephrine, and eventually a mixed combinations of their secretion [1]. Conversely, about $1 \%$ of catecholamine-secreting tumors result asymptomatic, representing an incidental finding [2].

Pelvic PGLs occur in about $2 \%$ of cases [9] and bladder PGL represents less than $1 \%$ of all bladder neoplasms [84]. The first documented case of bladder PGL was reported by Zimmerman et al in 1953 [13], and since then, more than one hundred cases have been described worldwide. However, the extreme variability of clinical presentation often can "mime" other pathological conditions, raising the interests of different specialists (urologists, gynecologists, pediatricians, radiologists, and general practitioners). This 
might lead to delay or lack of diagnosis, and, therefore, to an increased incidence of complications. Moreover, Clinical Guidelines Committee of the Endocrine Society recommends repeated measurements of plasma-free metanephrines or 24-hour urinary fractionated metanephrines for initial biochemical screening of suspected PHEO and PGL [1].

It is necessary to pinpoint that, unfortunately, these determinations do not reach a $100 \%$ of sensitivity and specificity, and they could cause false negative results because catecholamines secretion might be sporadic or even undetectable, mainly in asymptomatic patients [86]. Our two cases well document the absence of detectable 24-h urinary metanephrines and VMA in repeated measurements, despite the histological confirm of PGL diagnosis. An extra-adrenal localization of PGL results in a clinical displacement between dopaminergic or noradrenergic over-production; an enhanced turnover of those metabolites could moreover aggravate clinical diagnosis because of repeated false-negative metanephrines determination. Furthermore, MIBG Scintigraphy has limited use in these cases because of sub-optimal sensitivity, especially in metastatic PGLs and those carrying succinate-dehydrogenase (SDH)x mutations. In particular, Brito et al. had observed that functional imaging in pheochromocytoma had small additive value to morphological imaging such as CT or MR; further research should evaluate impact of functional imaging in specific subgroups such as metastatic or extra-adrenal PGLs [87].

Atypical clinical presentation and complex management of our two patients has been an hint to elaborate an extended research on international literature on pelvic and bladder PGLs; basing on these clinical and biochemical issues in the pelvic PGL recognition, which lead relentlessly to a delayed diagnosis and treatment, we decided to perform this short review.

According to the case reports in literature, the cases reported concerned two females, evaluated at our Specialized Unit for uncontrolled and paroxysmal hypertension, which represents the more frequent sign of disease, but unfortunately often not investigated. However, if promptly recognized and treated this disease can lead to a full clinical and biochemical recovery. Our case reports, indeed, confirm the outcomes reported in PGLs and PHEOs literature (Figure 4). In more detail, according to Primary Aldosteronism Surgery Outcome (PASO) criteria [88], used for detection of primary aldosteronism cure after adrenalectomy, we performed a subanalysis to evaluate the effect of surgical treatment of PGLs in terms of clinical and biochemical remission. The group $A$ included patients with clinical and biochemical remission; the group $B$ only biochemical values normalization (e.g. plasma and/or 24-hour catecholamines and/or metanephrines) with symptoms and signs persistence, mostly represented by high BP values. In the group $C$ we included patients with neither biochemical nor clinical recovery, and in the group $D$ patients dead during follow-up. We found that up to $50 \%$ of patients had complete clinical and biochemical recovery after surgical tumor excision; $2.3 \%$ showed only biochemical remission, with clinical persistence of signs and symptoms, $19.1 \%$ had no remission, and $19.1 \%$ died because of surgery-related complications (Figure 4). We did not find any difference in terms of age between group A and group D (40.9 \pm 18.7 vs. $40.7 \pm 19.2$ years), but a greater prevalence of metastatic disease at diagnosis was found in the group $D$ compared to A (66.7 vs. $20.8 \%, p<0.05)$. Furthermore, we observed that multi-localized tumors at first diagnosis were strongly associated to a poor prognosis, because for these forms it could not be planned a curative and 
resolute surgical treatment, and because of the biochemical persistence (e.g. catecholamines secretion) leads to fatal cardiovascular events (i.e. dilatative cardiomyopathy).

In summary, our study improves upon previous reviews, which was dated and focalized mainly on bladder PGL [11-85]. For example, Tsai et al. includes one study dating back to 1911, and then eleven studies between 1989 and 2000 [17], while Beilan et al. [85] included 80 studies between 1980 and 2012; therefore, we offer a more updated view for analyzing contemporary outcomes. Our study used a multitude of demographics to depict the disease process of pelvic and bladder PGL, including presenting signs and symptoms, tumor functionality and size, treatment modality, and outcomes. From our literature review, according to previous researches [9, 11-85], it was found that pelvic and bladder PGLs are more frequent in females, rarely metastatic, and even more rarely associated to genetic mutations. Therefore, the multilocalized forms are characterized by worst prognosis and higher risk of death for cardiovascular complications, possibly associated to systemic and persistent effect of catecholamines oversecretion. Pelvic and bladder PGLs manifestations are vary and complex; as reported by our research $54.2 \%$ of cases showed a diagnosis of hypertension, while more than $30 \%$ presented hematuria and headache, and micturition attacks were reported in only 30 cases. Furthermore, pelvic and bladder PGLs are often undiagnosed until later in life, when flank pain and hematuria occurred, probably because of their unusual localization. The clinical evidences suggest that some patients could underestimate and could not be worried about adrenergic and noradrenergic symptoms, such as paroxysmal headache or palpitations or high BP values. These aspects could extend investigations, as happened in our first patient, which even got a psychiatric consult before a proper diagnosis. Therefore, catecholamine overproduction could be misdiagnosed in patients who complain of anxiety or moreover depressive behavior disorder. Physicians must be careful and cautious to patients with unexplained hypertension, headache, palpitations, and anxiety, associated to "compression-effect" symptoms (i.e. hematuria and/or recurrent cystitis). In our experience, as it has been demonstrated in our case reports, it is important to do not underestimate atypical presentation of pelvic and bladder PGLs and to do not neglect latent signs or symptoms. We recommend a detailed anamnesis and physical examination to detect subtle symptoms which are suggestive of cathecolaminergic spill-over. Moreover, cases of multiple and metastatic lesions are more aggressive and characterized by a worst prognosis; in these situations proper follow-up and treatment is mandatory to avoid the onset of complications. Actually, postoperative follow-up of these patients remains controversial at best, with no established guidelines or algorithms on appropriate management of PGLs. Limitations our study consists that most cases and series reports were extremely eterogeneous, some of them were anecdotal; some manuscripts missed a section with a well established and clear diagnosis, treatment and follow-up of pelvic and bladder PGLs. This reflects, in our opinion, a missing section in guidelines [1] in proper managing of these neoplasms' subgroup. There are missing data in further subgroups analysis. Actually a unique systematic register to describe pelvic and bladder PGLs does not exist. More evidences could be discovered if future efforts were directed in a prospective view of the problematique. Furthermore, in our view, in the diagnosis of multi-localized and malignant PGLs, could be suggested a close follow-up with monthly catecholamines and metanephrines levels and imaging every 6 months -1 year. 
Furthermore, it is important in these patients to consider genetic mutations in patients with multiple and familial PGLs. In particular, physicians may consider SDHA germline mutation in patients with skull base, neck or thoracic, abdominal, and pelvic localization, even if SDHB and SDHA immunohistochemistry on tumoral tissue resulted negative (1).

\section{Conclusions}

Diagnosis of non-functioning pelvic and bladder paragangliomas is difficult, but the tumors should be suspected in patients who have hypertension, hematuria or mass effects due to the tumor growth in the pelvis and/or retroperitoneum. Physicians must be careful to read laboratory and imaging results because in pelvic and bladder PGLs false-negatives may not be underestimated. A genetic germline mutation screening is useful especially in those patients with multiple and metastatic neoplasms. A long term followup is advisable once a proper treatment has been managed. It would be helpful to standardize the reporting guidelines of pelvic PGL cases to better understand the natural process and outcomes.

\section{List Of Abbreviations}

ABPM: ambulatory blood pressure monitoring; BP: blood pressure; CT: computed tomography; MIBG: ${ }^{123}$ |metaiodobenzylguanidine MR: magnetic resonance; PGL: paraganglioma; PHEO: pheochromocytoma;

PASO: Primary Aldosteronism Surgery Outcome; PRISMA: Preferred Reporting Items of Systematic Review and Meta-analysis; SDH: succinate dehydrogenase; VMA: vanillyl mandelic acid

\section{Declarations}

\section{Ethics approval and consent to participate}

All procedures performed in studies involving human participants were in accordance with the 1964 Helsinki declaration and its later amendments or comparable ethical standards. Informed consent was obtained from all individual participants included in the study.

\section{Consent to publish}

All subjects expressed explicit and written consent to publish their data regarding this study.

\section{Availability of data and materials}

The data used to support the findings of this study are available from the corresponding author upon request.

\section{Competing interests}

The authors declare no conflict of interest.

\section{Funding}


No funding was obtained for this research

\section{Authors' contribution}

VB, LP, FO: protocol/project development, data collection or management, data analysis, and manuscript writing/editing. CL: protocol/project development and manuscript writing/editing. AC: manuscript writing/editing. VS: manuscript writing/editing. FO and LP: data analysis. FO: data collection or management and data analysis. VB: data collection or management. MC: manuscript writing/editing. GC: manuscript writing/editing. GDT: manuscript writing/editing. AC: manuscript writing/editing. MRT: manuscript writing/editing. LG, CL: protocol/project development and manuscript writing/editing.

\section{Acknowledgments}

The authors thank the participating patients who made this study possible. No relationship with industry to be disclosed. All authors have nothing to disclose.

\section{References}

1. Lenders WJ, Duh QY, Eisenhofer G, et al; Endocrine Society. (2014) Pheochromocytoma and paraganglioma: an endocrine society clinical practice guideline. J Clin Endocrinol Metab. 99:19151942. doi: 10.1210/jc.2014-1498.

2. Cotesta D, Petramala L, Serra V, et al. (2009) Clinical experience with pheochromocytoma in a single centre over 16 years. High Blood Press Cardiovasc Prev. 16:183-193. doi: 10.2165/11530430000000000-00000.

3. Prejbisz A, Lenders JW, Eisenhofer G, Januszewicz A. (2011) Cardiovascular manifestations of phaeochromocytoma. J Hypertens. 29:2049-2060. doi: 10.1097/HJH.0b013e32834a4ce9.

4. Zelinka T, Petrák O, Turková $\mathrm{H}$, et al. (2012) High incidence of cardiovascular complications in pheochromocytoma. Horm Metab Res. 44:379-384. doi: 10.1055/s-0032-1306294.

5. Olmati F, Petramala L, Bisogni V, et al. (2018) A rare case report of hypertrophic cardiomyopathy induced by catecholamine-producing tumor. Medicine (Baltimore) 97:e13369. doi: 10.1097/MD.0000000000013369.

6. Streeten DH, Anderson GH Jr. (1996) Mechanisms of orthostatic hypotension and tachycardia in patients with pheochromocytoma. Am J Hypertens. 9:760-769. DOI: 10.1016/0895-7061(96)00057-x.

7. Hannah-Shmouni F, Pacak K, Stratakis CA. (2017) Metanephrines for Evaluating Palpitations and Flushing. JAMA. 318:385-386. doi: 10.1001/jama.2017.5926.

8. Thosani S, Ayala-Ramirez M, Román-González A, et al. (2015) Constipation: an overlooked, unmanaged symptom of patients with pheochromocytoma and sympathetic paraganglioma. Eur $\mathrm{J}$ Endocrinol. 173:377-387. doi: 10.1530/EJE-15-0456.

9. Royo P, de Luis E, Manero MG, Velloso MJ, Toledo G, Alcázar JL. (2007) Pelvic paraganglioma. J Ultrasound Med. 26:261-265. 
10. Liberati A, Altman DG, Tetzlaff J, et al. (2009) The PRISMA statement for reporting systematic reviews and meta-analyses of studies that evaluate healthcare interventions: explanation and elaboration. BMJ. Jul 21;339:b2700. doi:10.1136/bmj.b2700.

11. Plouin PF, Gimenez-Roqueplo AP. (2006) Pheochromocytomas and secreting paragangliomas. Orphanet J Rare Dis. 1:49. DOI: 10.1186/1750-1172-1-49.

12. Wick RM. (2000) Neuroendocrine neoplasia. Current concepts. Am J Clin Pathol. 113:331-335. DOI: 10.1309/ETJ3-QBUK-13QD-J8FP

13. Priyadarshi V and Pal DK. (2015) Paraganglioma of urinary bladder. Urol Ann. 7:402-404. doi: 10.4103/0974-7796.152058.

14. Zimmerman IJ, Biron RE, Macmahon HE. (1953) Pheochromocytoma of the urinary bladder. N Engl J Med. 249:25-26. DOI: 10.1056/NEJM195307022490106.

15. Yi C, Han L, Yang R, et Yu J. (2017) Paraganglioma of the renal pelvis: a case report and review of literature. Tumori. 103:e47-e49.

16. Amulya S, Dhar YG, Manjushree S, Arvind S. (2017) Extra-adrenal retroperitoneal paraganglioma: report of a rare case. J Clin Diagn Res. 2:146-147. doi: 10.7860/JCDR/2014/10133.5138.

17. Cao G, Mendez J, Navacchia D. (2017) Malignant extra-adrenal pelvic paraganglioma in a pediatric patient. Ecancermedicalscience. 11:761. doi: 10.3332/ecancer.2017.761.

18. Tsai CC, Wu WJ, Chueh KS, et al. (2011) Paraganglioma of the urinary bladder first presented by bladder bloody tamponade: two case reports and review of the literatures. Kaohsiung J Med Sci. 27:108-113. doi: 10.1016/j.kjms.2010.05.005.

19. Geng JH, Huang SP, Shen JT, et al. (2014) Paraganglioma of the urinary bladder with pelvic metastases. Urological Science. 25;91-94.

20. Chang $\mathrm{Y}$, Chiang I, Chen $\mathrm{CH}$, et al. (2015) Paragangliomas of the urinary bladder: A report of 6 cases and review of the literature. Urological Science. 26:111-114.

21. Dattatrya JY, Vedpalsingh TH, Ravikant SU, et al. (2015) Paraganglioma of Urinary Bladder Presenting as An Early Preeclampsia with Successful Perinatal Outcome After Surgery: A Case Report and Review of Literature. J Clin Diagn Res. 9:PD01-PD02. doi: 10.7860/JCDR/2015/14306.6420.

22. Demirkesen O, Cetinel B, Yaycioglu O, et al. (2000) Unusual cause of early preeclampsia: bladder paraganglioma. Urology. 56:154.

23. Parmar K, Chandna A, Kumar S. (2019) Retroperitoneal paraganglioma: a chameleon masquerading as an adrenal pheochromocytoma. Ann R Coll Surg Engl. 101:e62-e65. doi: 10.1308/rcsann.2018.0193.

24. Beilan J, Lawton A, Hajdenberg J, Rosser CJ. (2013) Locally advanced paraganglioma of the urinary bladder: a case report. BMC Res Notes. 6:156. doi: 10.1186/1756-0500-6-156.

25. Pedroso C, Robalo R, Sereno P, et al. (2015) A rare abdomino-pelvic tumor: paraganglioma. Acta Medica Port. 28:114-116.

26. Di Daniele N, Canale MP, Tesauro M, et al. (2012) Preoperative embolization reduces the risk of catecholamine release at the time of surgical excision of large pelvic extra-adrenal sympathetic paraganglioma. Case Rep Endocrinol. 481328. doi: 10.1155/2012/481328. 
27. Kumar S, Parmar KM, Prasad S, Rani J. (2014) Malignant Pelvic Pheochromocytoma Presenting as Non Functioning Kidney and Accelerated Hypertension: A Rare Presentation. Case Rep Nephrol. 985615.

28. El Khoury F, Jour I, Malaeb B, Assaf G. (2012) Bladder paraganglioma. A case report. J Med Liban. 60:182-184.

29. Cai Y, Li HZ, Zhang YS. (2015) Successful Treatment of Coexisting Paraganglioma of the Retroperitoneum and Urinary Bladder by Intermediate-Dose 131I-MIBG Therapy: A Case Report. Medicine (Baltimore) 94:e1686. doi: 10.1097/MD.0000000000001686.

30. de Paula Miranda E, Lopes RI, Padovani GP, et al. (2016) Malignant paraganglioma in children treated with embolization prior to surgical excision. World J Surg Oncol. 14:26. doi: 10.1186/s12957-0160778-8.

31. Imperatore V, Creta M, Di Meo S, et al. (2017) Incidentally discovered pelvic paraganglioma: A case report. Arch Ital Urol Androl. 89:319-320. DOI: 10.4081/aiua.2017.4.319

32. Persec Z, Buković D, Persec J, et al. (2012) Paraganglioma of the urinary bladder-clinicopathological, immunohistochemical and electron microscopy analysis-a case report. Coll Antropol. 36:1041-1043.

33. Kuscu E, Oktem M, Eroglu D, et al. (2005) Pelvic retroperitoneal paraganglioma mimicking an ovarian mass. Eur J Gynaecol Oncol. 26:219-220.

34. Kumar S, Parmar KM, Singh S, Rani J. (2014) Pelvic pheochromocytoma mimicking as urinary bladder pheochromocytoma: looking beyond the obvious. J Clin Imaging Sci. 4:56. doi: 10.4103/21567514.143409.

35. Rayamajhi SJ, Mittal BR, Shukla J, et al. (2015) Recurrent Urinary Bladder Paraganglioma Detected on 68Ga DOTANOC PET/CT. Clin Nucl Med. 40:e490-491. doi: 10.1097/RLU.0000000000000910.

36. Lacefield E, Raheem OA, Cox R, et al. (2015) Composite Paraganglioma and Neuroblastoma of the Urinary Bladder: A Rare Histopathological Entity. Curr Urol. 8:208-211. doi: 10.1159/000365718.

37. Lin WC, Wang HY, Chang CW, et al. (2012) Retroperitoneal paraganglioma manifesting as paralytic ileus: a case report. J Med Case rep. 6:158. doi: 10.1186/1752-1947-6-158.

38. Shah VB, Bhandare AT. (2015) A rare case of malignant paraganglioma of urinary bladder. Indian J Pathol Microbiol. 58:235-237. doi: 10.4103/0377-4929.155329.

39. Kumar S, Pragatheeswarane M, Sharma AP, et al. (2017) Expanding the horizon of robotic surgery to large pelvic paraganglioma. J Robot Surg. 11:247-250. doi: 10.1007/s11701-016-0648-y.

40. Taue R, Takigawa $\mathrm{H}$, Sinotou K, et al. (2001) A case of pelvic malignant paraganglioma. Int J Urol. 8:715-718.

41. Thambugala GM, Fulham MJ, Mohamed A. (2007) Positron emission tomography-computerized tomography findings in a urinary bladder paraganglioma. Australas Radiol 51:B45-B47. DOI: 10.1111/j.1440-1673.2007.01846.x

42. Vellar ID, Chmiel R, Cahill J. (1978) Localization of a phaeochromocytoma situated in the pelvis by radionuclide scanning. $\mathrm{Br} \mathrm{J}$ Surg. 65:25-26. 
43. Athyal RP, Al-Khawari $\mathrm{H}$, Arun $\mathrm{N}$, et al. (2007) Urinary bladder paraganglioma in a case of von HippelLindau disease. Australas Radiol. 51:B67-70. DOI: 10.1111/j.1440-1673.2007.01758.x

44. Adejimi O. Adeniji, MD. (2009) Urinary bladder pheochromocytoma. Applied Radiology.

45. Onishi T, Sakata Y, Yonemura S, Sugiumura Y. (2003) Pheochromocytoma of the urinary bladder without typical symptoms. Int J Urol. 10:398-400.

46. F. Doran, S. Varinli, Y. Bayazit, et al. (2002) Pheochromocytoma of the urinary bladder. APMIS. 110:733736.

47. Chen YC, Su YC, Tzang JE, et al. (2009) A woman with persistent chest pain and palpitations after coronary stenting. Kidney Int. 75:1361-1362. doi: 10.1038/ki.2009.120.

48. Zhou M, Epstein JI, Young RH. (2004) Paraganglioma of the urinary bladder: a lesion that may be misdiagnosed as urothelial carcinoma in transurethral resection specimens. Am J Surg Pathol. 28:94100.

49. Shono T, Sakai H, Minami Y, et al. (1999) Paraganglioma of the urinary bladder: a case report and review of the Japanese literature. Urol Int. 62:102-105. DOI: 10.1159/000030367.

50. Sanjoaquin M, Fraile J, Gutierrez A, et al. (2000) Hypertensive crisis during a transurethral resection of the bladder: non diagnosed bladder paraganglioma. Anesth Analg. 90:556-558.

51. Baima C, Casetta G, Vella R, Tizzani A. (2000) Bladder pheochromocytoma: a 3-year follow-up after transurethral resection (TURB). Urol Int. 65:176-178. DOI: 10.1159/000064868.

52. Bhalani SM, Casalino DD, Manvar AM. (2011) Paraganglioma of the bladder. J Urol. 186:279.280. DOI: 10.1016/j.juro.2011.04.032.

53. De Pasquale V, Magistrelli A, Diomedi Camassei F, Caione P. (2011) Unusual bladder mass in a 14-year old boy: bladder paraganglioma. Urol Int. 86:117-120. doi: 10.1159/000320840.

54. Mun K, Pailoor J, Chan KS, Pillay B. (2009) Extra-adrenal paraganglioma: presentation in three uncommon locations. Malays J Pathol. 31:57-61.

55. Kang SS, Kang SH, Choi H, et al. (2011) Robot Assisted Partial Cystectomy of a Bladder Pheochromocytoma. Urol Int. 81:241-244. doi: 10.1159/000324269.

56. Naguib M, Caceres M, Thomas CR Jr, et al. (2002) Radiation treatment of recurrent pheochromocytoma of the bladder: case report and review of literature. Am J Clin Oncol. 25:42-44.

57. Yoshida S, Nakagomi K, Goto S, Kobayashi S. (2004) Malignant pheochromocytoma of the urinary bladder: effectiveness of radiotherapy in conjunction with chemotherapy. Int J Urol. 11:175-177.

58. Kovacs K, Bell D, Gardiner GW, et al. (2005) Malignant paraganglioma of the urinary bladder: immunohistochemical study of prognostic indicators. Endocr Pathol. 16:363-369.

59. Zwahlen D, Fishman PN, Honey J, et al. (2007) Malignant pheochromocytoma of the urinary bladder. Can J Urol. 14:3455-3457.

60. Huang KH, Chung SD, Chen SC, et al. (2007) Clinical and pathological data of 10 malignant pheochromocytomas: long-term follow up in a single institute. Int J Urol. 14:181-185. DOI: 10.1111/j.1442-2042.2007.01687.x. 
61. Havekes B, Corssmit EP, Jansen JC, et al. (2007) Malignant paragangliomas associated with mutations in the succinate dehydrogenase D gene. J Clin Endocr Metab. 92:1245-1248. DOI: 10.1210/jc.2006-1993.

62. Darlong V, Pandey R, Garg R, et al. (2012) Perioperative concerns of recurrent urinary bladder phaeochromocytoma with skeletal metastasis. Singapore Med J. 52:e40-41.

63. Manohar K, BR Mittal, A. Bhattacharya, et al. (2012) A rare case of malignant urinary bladder paraganglioma with distant metastases demonstrated by 18F-FDG PET/CT. Clin Nucl Med. 37:e148e149. DOI: 10.1097/RLU.0b013e318238f71a.

64. Feng N, Li X, Gao H, et al. (2013) Urinary bladder malignant paraganglioma with vertebral metastasis: a case report with review of the literature. Chin J Cancer. 32:624-628. DOI: 10.5732/cjc.012.10317.

65. Maeda M, Funahashi Y, Katoh M, et al. (2013) Malignant bladder pheochromocytoma with SDHB genetic mutation. Aktuelle Urol. 44:381-382. DOI: $10.1055 / \mathrm{s}-0033-1345147$.

66. Gkikas C, Ram M, Tsafrakidis P. (2016) Urinary Bladder Paraganglioma and Concomitant Metastatic Lung Cancer. A Case Report. Urol Case Rep. 5:17-19. DOI:10.1016/j.eucr.2015.12.002.

67. You D, Ren R, Chen E, et al. (2016) Radiotherapy for urinary bladder pheochromocytoma with invasion of the prostate: A case report and literature review. Mol Clin Oncol. 4:1060-1062. DOI: 10.3892/mco.2016.820.

68. Sherwani P, Anand R, Narula MK, et al. (2015) Concurrent nonfunctional paraganglioma of the retroperitoneum and urinary bladder: A case report with literature review. Indian J Radiol Imaging. 25:198-201. DOI: 10.4103/0971-3026.155879.

69. Peng C, Bu S, Xiong S, et al. (2015) Non-functioning paraganglioma occurring in the urinary bladder: A case report and review of the literature. Oncol Lett. 10:321-324. DOI: 10.3892/ol.2015.3222.

70. Lazareth H, Cohen D, Vasiliu V, et al. (2017) Paraganglioma of the bladder in a kidney transplant recipient: A case report. Mol Clinl Oncol. 6:553-555. DOI: 10.3892/mco.2017.1182.

71. Henderson SJ, Kearns PJ, Tong CMC et al. (2015) Patients With Urinary Bladder Paragangliomas: A Compiled Case Series From a Literature Review for Clinical Management. Urology. 85:e25-e29. DOI: 10.1016/j.urology.2014.11.006.

72. Mahjoubi Z, BehRhouma S, Bibi M, et al. (2018) Atypical calcified paraganglioma of the urinary bladder: A new case report. Urol Case Rep. 20:108-110. DOI: 10.1016/j.eucr.2018.07.024.

73. A. Mithqal, P. Darvishi, P. Rehm. (2017) MIBG Localization of a Subclinical Paraganglioma of the Bladder. Clin Nucl Med. 42:e196-e198. DOI: 10.1097/RLU.0000000000001562.

74. Iwamoto G, Kawahara T, Tanabe M, et al. (2017) Paraganglioma in the bladder: a case report. J Med Case Rep. 11:306. DOI: 10.1186/s13256-017-1473-2.

75. Spessoto LC, Vasilceac FA, Padilha TL, et al. (2016) Incidental Diagnosis of Nonfunctional Bladder Paraganglioma. Urol Case Rep. 4:53-54. DOI: 10.1016/j.eucr.2015.09.007.

76. El-Tholoth HS, Al Rasheedi S, Alharbi F, et al. (2018) Paraganglioma of Urinary Bladder Managed by Laparoscopic Partial Cystectomy in Conjunction with Flexible Cystoscopy: A Case Report. J of Endourol Case Rep. 4:15-17. DOI: 10.1089/cren.2017.0132. 
77. Srirangalingam U, Banerjee A, Patki P, et al. (2017) Succinate Dehydrogenase B (SDHB)-Associated Bladder Paragangliomas. Clin Genitourin Cancer. 15:131-136. DOI: 10.1016/j.clgc.2016.06.006

78. Quist EE, Javadzadeh BM, Johannesen E, et al. (2015) Malignant paraganglioma of the bladder: A case report and review of the literature. Pathol Res Pract. 211:183-188. DOI: 10.1016/j.prp.2014.10.009.

79. Stigliano A, Lardo P, Cerquetti L, et al. (2018) Treatment responses to antiangiogenetic therapy and chemotherapy in nonsecreting paraganglioma (PGL4) of urinary bladder with SDHB mutation. A case report. Medicine (Baltimore). 97:e10904. DOI: 10.1097/MD.0000000000010904.

80. Verma A, Pandey D, Akhtar A, et al. (2015) Non-Functional Paraganglioma of Retroperitoneum Mimicking Pancreatic Mass with Concurrent Urinary Bladder Paraganglioma: An Extremely Rare Entity. J Clin Diagn Res. 9:XD09-XD11. DOI: 10.7860/JCDR/2015/11156.5570.

81. Williams P, Siref L, Feloney M. (2017) Pheochromocytoma of the bladder. JAAPA. 3023-25. DOI: 10.1097/01.JAA.0000522134.68445.50.

82. Gyftopoulos K, Perimenis P, Ravazoula Z, et al.. (2000) Pheochromocytoma of the Urinary Bladder Presenting Only with Macroscopic Hematuria, Urol Int. 65:173-175. DOI: 10.1159/000064867.

83. Yadav S, Banerjee I, Tomar V, Yadav SS. (2016) Pelvic paraganglioma: a rare and unusual clinical presentation of paraganglioma. BMJ Case Rep. pii:bcr2015212851. DOI: 10.1136/bcr-2015-212851.

84. Bohn OL, Pardo-Castillo E, Fuertes-Camilo M, et al. (2001) Urinary Bladder Paraganglioma in Childhoold: A case Report and Review of the Literature. Pediatr Dev Pathol. 14:327-332. DOI: 10.2350/10-10-0926-CR.1.

85. Pastor-Guzmàn, S. Lòpez-Garcìa, J.M. Giménez-Bachs, et al. (2004) Paraganglioma of the bladder: controversy regarding treatment. Urol Int. 73:270-274. DOI: 10.1159/000080841.

86. Beilan JA, Lawton A, Hajdenberget J, Rosser CJ. (2013) Pheochromocytoma of the urinary bladder: a systematic review of the contemporary literature. BMC urology. 13:22. DOI: 10.1186/1471-2490-13-22.

87. Petramala L, Galassi M, D'ermo G, et al. (2017) Nonfunctioning adrenal pheochromocytoma incidentally discovered associated with renal oncocytoma. Journal of Onco-Nephrology. 1:62-65. DOI: 10.5301/jo-n.5000003.

88. Brito JP, Asi N, Gionfriddo MR, et al. (2015) The incremental benefit of functional imaging in pheochromocytoma/parganglioma: a systematic review. Endocrine. 50(1):176-86. doi: 10.1007/s12020-015-0544-7.

89. Williams TA, Lenders JW, Mulatero P, et al. (2017) Outcomes after adrenalectomy for unilateral primary aldosteronism: an international consensus on outcome measures and analysis of remission rates in an international cohort. Lancet Diabetes Endocrinol. 5:689-699. DOI: 10.1016/S2213-8587(17)30135-3

\section{Table}

Table 1. 


\begin{tabular}{|c|c|}
\hline Baseline characteristics & $\mathrm{N}=131$ \\
\hline Mean age (years) (mean \pm SD) & $40.4 \pm 18.8$ \\
\hline Sex $(M: F)$ & 63:66 \\
\hline Tumors size $(\mathrm{mm})($ mean $\pm \mathrm{SD})$ & $48.1 \pm 32.7$ \\
\hline Metastasis (n, \%) & $45(34.3 \%)$ \\
\hline Syndromic form (n, \%) & $10(7.6 \%)$ \\
\hline \multicolumn{2}{|l|}{ Genetic mutations (n): } \\
\hline NF1 & 1 \\
\hline VHL & 1 \\
\hline SDHB & 8 \\
\hline Uptake to ${ }^{123}$ I-Metaiodobenzylguanidine scintigraphy (n, \%) & $25(19.1 \%)$ \\
\hline Signs and symptoms (n, \%) & $\mathbf{N}=131$ \\
\hline None & $6(4.6 \%)$ \\
\hline Hypertension & $71(54.2 \%)$ \\
\hline Haematuria & $46(35.1 \%)$ \\
\hline Headache & $44(33.6 \%)$ \\
\hline Palpitations & $27(20.6 \%)$ \\
\hline Micturition attacks & $30(22.9 \%)$ \\
\hline Sweating & $13(9.9 \%)$ \\
\hline Pain & $17(13.0 \%)$ \\
\hline Syncope & $3(2.3 \%)$ \\
\hline Chest pain & $3(2.3 \%)$ \\
\hline Hypotension & $2(1.6 \%)$ \\
\hline Preeclampsia & $2(1.6 \%)$ \\
\hline Urinary retention & $6(4.6 \%)$ \\
\hline Hydroureteronephrosis & $2(1.6 \%)$ \\
\hline Recurrent Cystitis & $3(2.3 \%)$ \\
\hline Malaise & $2(1.6 \%)$ \\
\hline Dizziness & $2(1.6 \%)$ \\
\hline Blurred vision & $3(2.3 \%)$ \\
\hline Others & $9(16.1 \%)$ \\
\hline Metabolites & Positive (n, \%) \\
\hline 24-hour urinary metanephrines & $59(45.1 \%)$ \\
\hline Plasma catecholamines and metanephrines & $56(42.7 \%)$ \\
\hline Plasma dopamine & $12(9.1 \%)$ \\
\hline Neurono-Specific Enolase (NSE) & $3(2.3 \%)$ \\
\hline Cromogranine A & $2(1.6 \%)$ \\
\hline Vanillyl mandelic acid & $24(18.3 \%)$ \\
\hline
\end{tabular}


Baseline characteristics, clinical manifestations, and baseline metabolites of 131 cases of pelvic and bladder PGLs.

\section{Figures}

PubMed advanced research:

a. Search terms: "pelvic paraganglioma", "bladder paraganglioma", "extraadrenal pheochromocytomas",

b. Publication date: from January 1954 to February 2019,

c. Subjects: humans

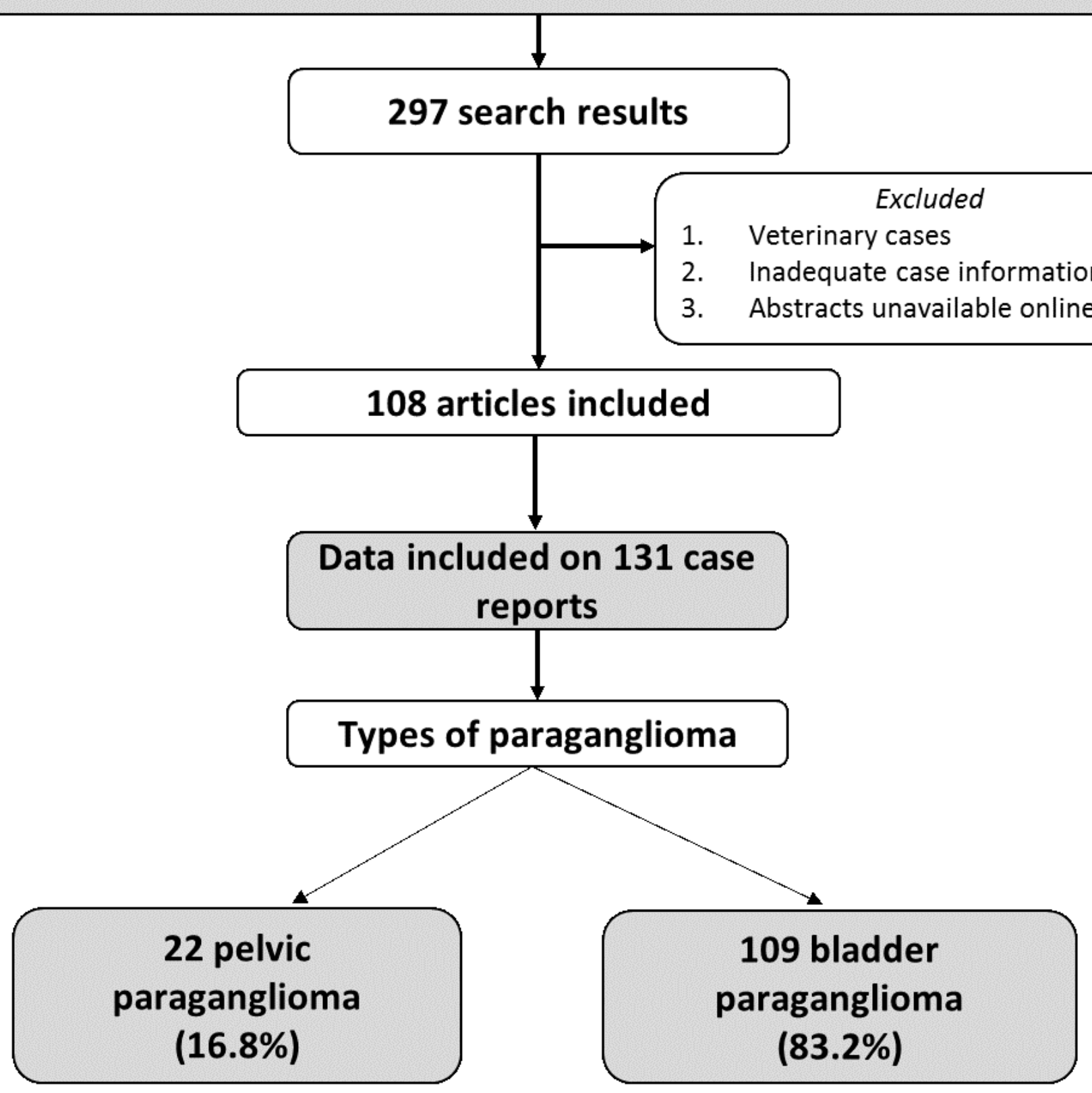

Figure 1 
Synopsis of literature review for pelvic and bladder PGLs [10-118].
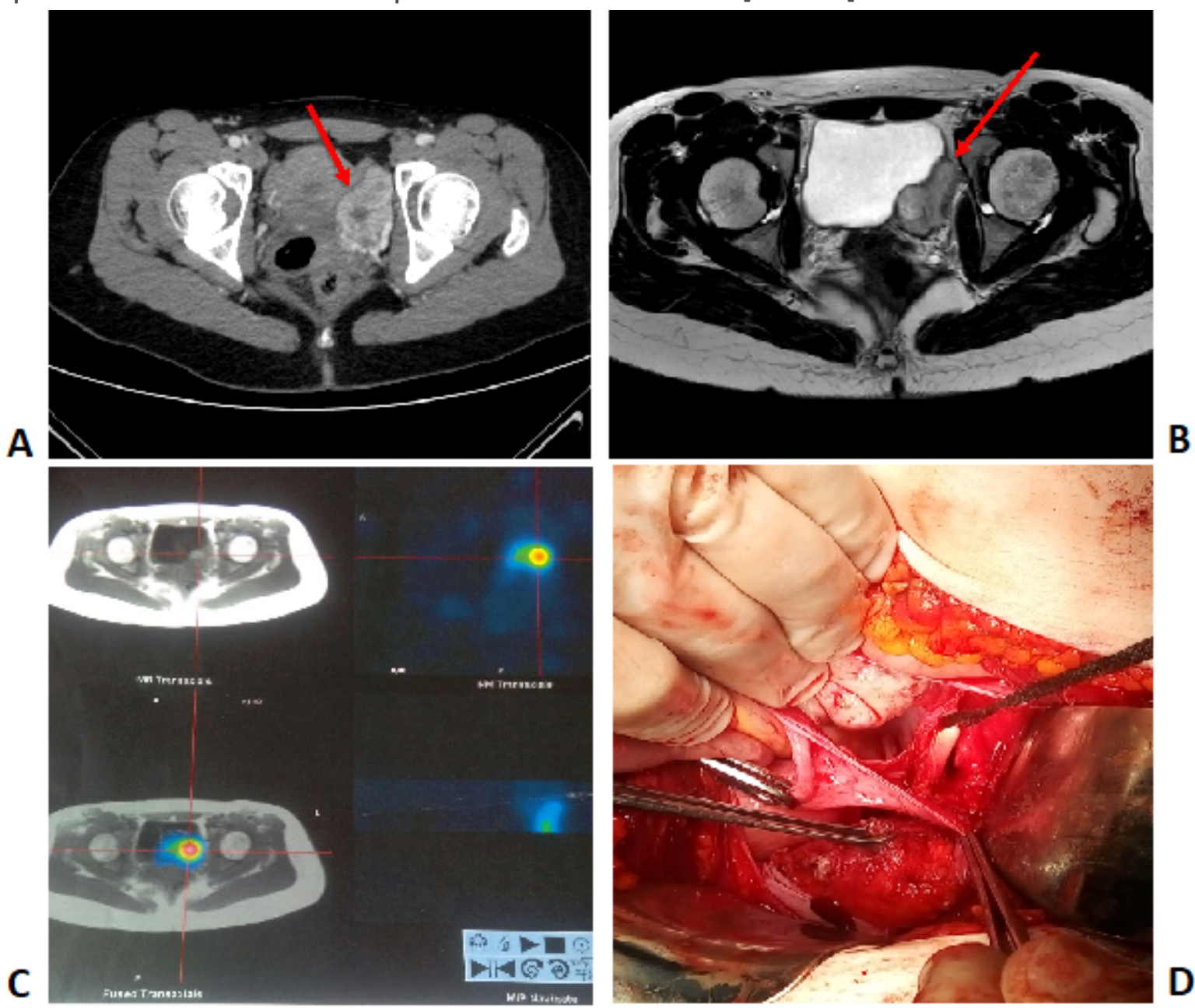

Figure 2

Case 1: Figure in panel A shows the first CT scan performed before the admission to our Unit; the red arrow indicate the pelvic lesion. In the panel B is evident the PGL mass abutting into the bladder (red arrow), successively confirmed by the 123I-MIBG scintigraphy (panel C). Panel D shows a laparotomic surgery, during which the bladder PGL was removed. 

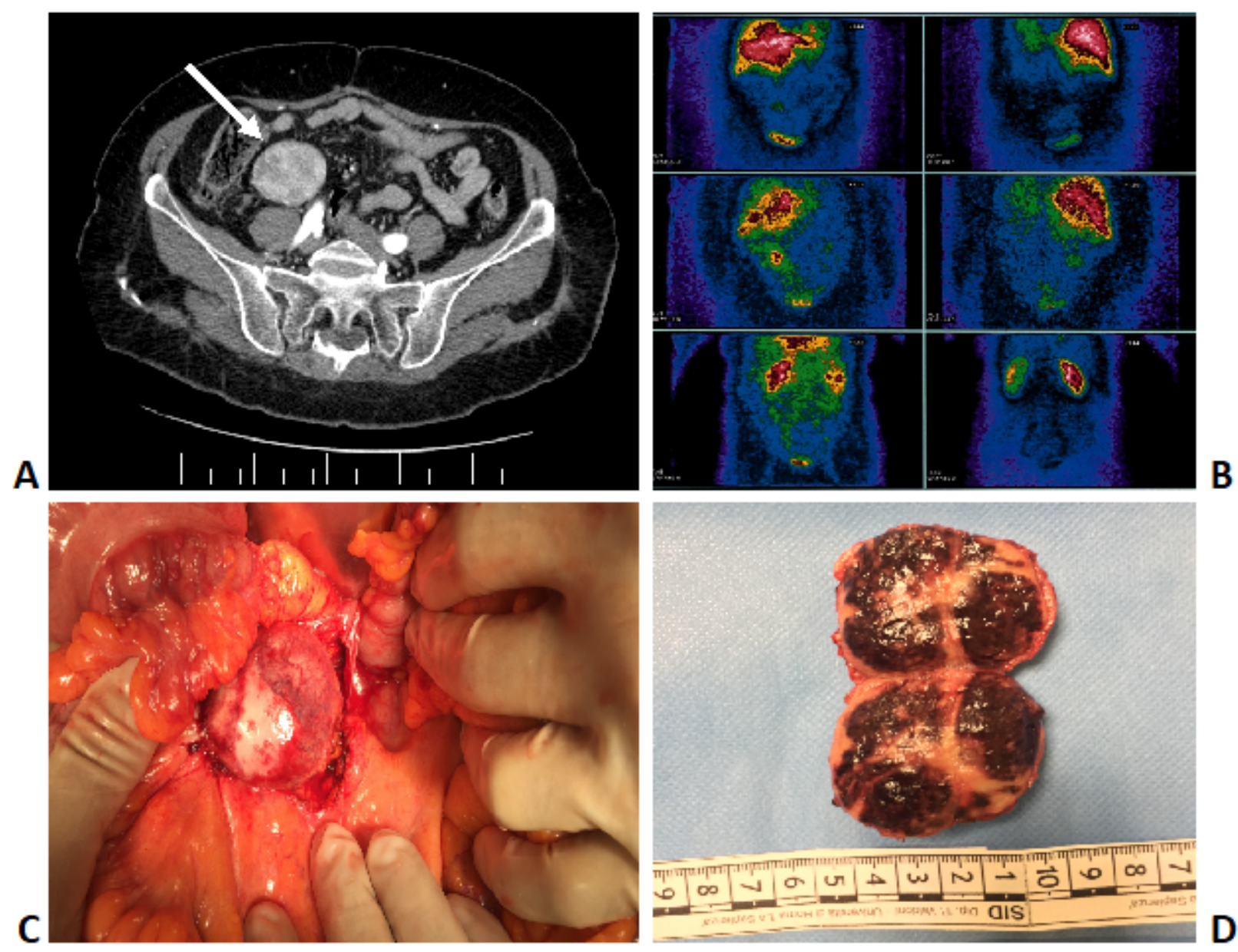

\section{Figure 3}

Case 2: Panel A shows the CT scan with iodate contrast, in which is highlighted the well-delimitated right pelvic mass (white arrow). In the panel B, the 123I-MIBG scintigraphy shows the high contrast uptake of the pelvic lesion. In the panel $C$ is represented a moment of laparotomic surgery. Panel $D$ shows the size of pelvic PGL removed. 


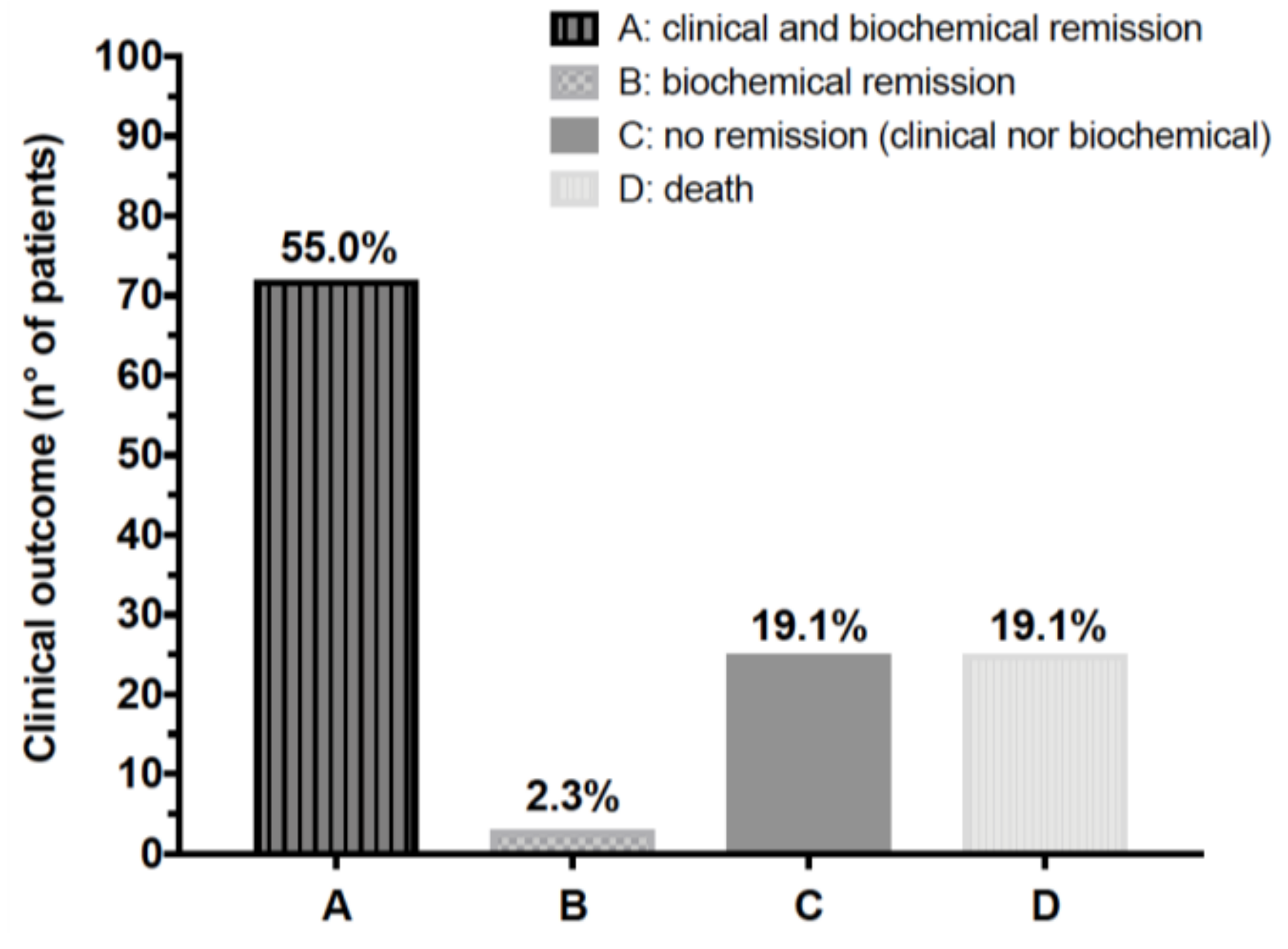

Figure 4

Subanalysis of clinical outcomes of surgical treatment of pelvic and bladder PGLs in terms of clinical and biochemical remission disease [124]. In six cases (4.6\%) were not reported clinical nor biochemical outcome. 